\title{
Ethnicity Influences Corpus Callosum Dimensions
}

\author{
Hilda Nouri Hosseini, ${ }^{1}$ Mohammad Reza Mohammadi, ${ }^{2}$ Mohsen Aarabi, ${ }^{3}$ \\ Narges Mohammadi, ${ }^{4}$ and Mohammad Jafar Golalipour $\mathbb{D}^{5}$ \\ ${ }^{1} 5$ Azar Hospital, Golestan University of Medical Sciences, Gorgan, Iran \\ ${ }^{2}$ Department of Neurosurgery, Golestan University of Medical Sciences, Gorgan, Iran \\ ${ }^{3}$ Department of Epidemiology, Mazandaran University of Medical Sciences, Sari, Iran \\ ${ }^{4}$ Gorgan Congenital Malformations Research Center, Golestan University of Medical Sciences, Gorgan, Iran \\ ${ }^{5}$ Gorgan Congenital Malformations Research Center, Department of Anatomical Sciences, \\ Golestan University of Medical Sciences, Gorgan, Iran \\ Correspondence should be addressed to Mohammad Jafar Golalipour; mjgolalipour@yahoo.com
}

Received 16 January 2018; Revised 7 March 2018; Accepted 18 March 2018; Published 2 May 2018

Academic Editor: Mamede de Carvalho

Copyright (C) 2018 Hilda Nouri Hosseini et al. This is an open access article distributed under the Creative Commons Attribution License, which permits unrestricted use, distribution, and reproduction in any medium, provided the original work is properly cited.

Background and Objective. Corpus callosum (CC), the main white matter cable which connects two hemispheres of brain, is important in special procedures such as stereotaxic surgeries vary in size, in different populations. Determination of possible size differences in ethnical groups has special values. Patients and Methods. The size of the CC on midsagittal view was determined in 76 normal male subjects using MRI of brain hemispheres in northern Iran. The size of rostrum, body, splenium, length, and height of CC was measured for each subject. The width of the body of the corpus callosum $(B)$, the anterior to posterior length $(L)$ and the maximum height $(H)$ of the corpus callosum, and ratios $B / L$ and $B / H$ were also calculated. Results. The longitudinal dimensions of the CC were $70.21 \mathrm{~mm}$ and $74.05 \mathrm{~mm}$ in native Fars and Turkmens, respectively $(P<0.05)$. The heights were $25 \mathrm{~mm}$ and $25.75 \mathrm{~mm}$ in native Fars and Turkmen subjects, respectively. The width of CC in Turkmen people was significantly higher than native Fars people $(P<0.05)$. The Evans index in Turkmen group $(0.314)$ was significantly higher than in native Fars $(0.3)$. The $B / L$ and $B / H$ ratios were nonsignificantly different between two groups. Conclusion. The CC parameters vary in different ethnical groups in northern Iran.

\section{Background}

Corpus callosum the major interhemispheric commisure connects two brain hemispheres [1]. Corpus callosum has the main role in language, prosody, and functional connection between the motor and sensory cortices of brain hemispheres $[2,3]$.

Several diseases, including bipolar disorder [4], Alzheimer [5], Leukoaraiosis [6], and Williams's syndrome [7], can alter the corpus callosum size in human.

Also, morphological alterations of the corpus callosum were reported in some diseases including dyslexia [8], Tourette's syndrome [9], Down's syndrome [10], Depression [11], Schizophrenia [12], and HIV/AIDS [13].

Corpus callosum dimensions seems to be various in different ethnical or racial populations; therefore, determining corpus callosum dimensions and sex-related differences is important in the diagnosis of diseases [14].

Several studies have been performed on the size and shape of the CC of Caucasian population [1, 15-19] and some studies reported in Japanese [20, 21] and Indian populations [22-24] and not in Iranian ones according to race/ethnicity.

Two major ethnic groups (native Fars and Turkmen) are residing in Gorgan, Golestan province in northern Iran; Golestan province has a population of about 1.8 million. Fars group is the predominant inhabitant of this province. The Turkmen people originally are from central Asia who moved here 200 years ago, and because of their special cultural belief, they do not mix with other residential groups. Although several studies have reported the effect of ethnicity on brain size and cranial capacity [25-27], there is no report regarding corpus callosum dimensions according to ethnicity in Iran. 
Therefore, this study was carried out to evaluate the dimensions of the corpus callosum depending on the ethnical groups in healthy Iranian population.

\section{Materials and Methods}

This descriptive study was done on 76 (40 native Fars, 36 Turkmen) subjects admitted to the Kowsar MRI Center in Gorgan, northern Iran, from July 2012 to December 2012. Subjects' consent was obtained for the study along with a clearance from the institutional ethical committee.

The subjects consisted of 76 men (range: 35-43 years old) without any brain disorder on MRI, and neurological symptoms and history of drug and drinking were enrolled in the study.

Brain and corpus callosum dimensions were measured on MRI Unit (Siemens, Symphony, 1.5 Tesla). MR images were acquired in the axial and vertical and sagittal planes by using flair, T1, and T2 weighted sequences.

Using a midsagittal section of the cerebral hemispheres, the width of all parts, length, and the height of CC were measured for each subject. For determining the parts of CC the two lines including a line from the inferior borders of the splenium to rostrum and a vertical line extending to the first line were drawn. The width of the body of the corpus callosum $(B)$, the anterior to posterior length $(L)$ and the maximum height $(H)$ of the corpus callosum, and ratios $B / L$ and $B / H$ were evaluated.

Also, using axial T1-weighted (TR/TE300/25 ms) images, the Evans index (maximum distance between the two anterior horns/maximum transverse inner diameter of the skull at the same level) and the maximum width of the third ventricle were measured.

The two different persons independently performed measurement and calculation of indices and ratios. All cases were known as numbers and investigators did not have any information about them.

The differences among ethnical groups were evaluated using one-way analysis of variance followed by Fisher's protected least-square difference test. The $P$ value less than $5 \%$ was considered significant.

\section{Results}

The corpus callosum dimensions according to ethnicity are depicted in Table 1.

In addition, a significant difference of A-P length between males in two groups were seen $(P<0.001)$. Other differences between males in Fars and Turkmen were not statistically significant.

The mean values of the longitudinal dimension of the corpus callosum were 70.21 (95\% CI: 68.85-71.58) and $74.05 \mathrm{~mm}$ (95\% CI: $72.43-75.68) \mathrm{mm}$ in native Fars and Turkmen subjects, respectively $(P<0.0001)$.

The mean values for the height of the corpus callosum were 25 (95\% CI: 24.28-25.74) and $25.75 \mathrm{~mm}$ (95\% CI: 24.79-26.71) $\mathrm{mm}$ in native Fars and Turkmen subjects, respectively.
TABLE 1: Dimensions of corpus callosum in Iranian male population (Turkmen and native Fars) in north of Iran.

\begin{tabular}{|c|c|c|}
\hline & Mean & $95 \% \mathrm{CI}$ \\
\hline \multicolumn{3}{|l|}{ Age } \\
\hline Fars $(N=40)$ & 36.4 & $33.4-39.5$ \\
\hline Turkmen $(N=36)$ & 37.3 & $33.6-40.96$ \\
\hline \multicolumn{3}{|l|}{ Width of rostrum } \\
\hline Fars & 11.08 & $10.58-11.58$ \\
\hline Turkmen & 11.55 & $11.04-12.06$ \\
\hline \multicolumn{3}{|l|}{ Width of splenium } \\
\hline Fars & $11.06^{*}$ & $10.70-11.43$ \\
\hline Turkmen & $11.77^{*}$ & $11.25-12.30$ \\
\hline \multicolumn{3}{|l|}{ Width of body } \\
\hline Fars & 6.38 & $6.08-6.68$ \\
\hline Turkmen & 6.87 & $6.54-7.21$ \\
\hline \multicolumn{3}{|c|}{ Anterior to posterior length } \\
\hline Fars & $70.21^{* *}$ & $68.85-71.58$ \\
\hline Turkmen & $74.05^{* *}$ & $72.43-75.68$ \\
\hline \multicolumn{3}{|l|}{ Height } \\
\hline Fars & 25 & $24.28-25.74$ \\
\hline Turkmen & 25.75 & $24.79-26.71$ \\
\hline \multicolumn{3}{|l|}{$B / L$} \\
\hline Fars & 0.109 & $0.072-0.146$ \\
\hline Turkmen & 0.091 & $0.084-0.098$ \\
\hline \multicolumn{3}{|l|}{$B / H$} \\
\hline Fars & 0.256 & $0.244-0.268$ \\
\hline Turkmen & 0.27 & $0.252-0.287$ \\
\hline \multicolumn{3}{|l|}{ Evans index } \\
\hline Fars & $0.3^{* * *}$ & $0.295-0.306$ \\
\hline Turkmen & $0.314^{* * *}$ & $0.308-0.320$ \\
\hline
\end{tabular}

${ }^{*} P=0.033$ (difference between Fars and Turkmen males); ${ }^{* *} P<0.0001$ (difference between Fars and Turkmen males); ${ }^{* * *} P=0.001$ (difference between Fars and Turkmen males).

The mean value for the width of the splenium in Turkmen subjects was significantly higher than native Fars subjects $(P<0.033)$.

The mean value for the width of the body of the corpus callosum and the width of the rostrum in Turkmen subjects was nonsignificantly higher than native Fars subjects.

The mean value for Evans index in Turkmen subjects $(0.314)$ was significantly higher than native Fars subjects $(0.3)$ $(P<0.001)$.

The $B / L$ ratio in native Fars subjects was nonsignificantly higher than Turkmen subjects, but the $B / H$ ratio in Turkmen subjects was nonsignificantly higher than native Fars subjects.

\section{Discussion}

In recent years, most of the available studies have been carried out on MRI scans in various parts of the world concerning the diameters and morphology differences of corpus callosum [1, 14-24, 28-30]. 
This study showed evidence for ethnical dimorphism in length of CC, the width of the body, and the width of splenium and Evans index.

In Takeda study, using the MRI method, the length and height of CC were reported $69.7 \pm 4.15$ and $25.9 \pm 2.90 \mathrm{~mm}$ in Japanese males, respectively [21].

According to Bermudez and Zatorre study, the total area of CC was significantly larger in men, as we have anterior third and posterior midbody. However, in females, relatively anterior midbody and splenium were larger. According to Bermudez and Zatorre opinion, there was a clear document for regional differences in size and possible shape and position of the CC between the males and females [15].

In Indian males, the length and height of $\mathrm{CC}$ were reported as $7.57 \mathrm{~cm}$ and $3.27 \mathrm{~cm}$, respectively. Also, the splenium width size was $1.15 \mathrm{~cm}$. Furthermore, length, height, and most of the widths of CC of Indian people were more than the Japanese but the length and width of CC were less than those of Caucasians [23].

Mourgela et al. (2007) in Greece reported that there was a positive linear association between longitudinal and vertical length of the brain and the space of the CC from the frontal and occipital poles of brain hemisphere, although there was no significant correlation between the brain length with the CC length [1].

Lee et al. (2008) reported that the orders of the length of anterior-posterior commissure distance were varied in Caucasian, Asian, Black, and Hispanic populations. According to Lee's findings, the racial factor can significantly affect the ACPC distance [31].

Several studies reported that only longitudinal dimension of CC is higher in males [1,24].

In this study, longitudinal dimensions of $\mathrm{CC}$ were more than other studies $[1,21,24]$. Also, the width of CC was similar to other studies $[1,21]$.

In this study, the Evans index in Turkmen subjects was significantly higher than native Fars subjects.

The $B / L$ ratio in native Fars subjects was nonsignificantly higher than Turkmen subjects, but the $B / H$ ratio in Turkmen subjects was nonsignificantly higher than native Fars subjects which means that these parameters were higher than Takeda et al. (2003) in Japanese subjects.

In this study, the Evans index in Turkmen subjects was significantly higher than native Fars subjects. In our results regarding the ethnic groups Evans index in the box were more than Japanese [21].

This study showed evidence for ethnical dimorphism in length of CC, the width of the body, and width of splenium. Our results confirm previous studies which reported racial differences regarding CC parameters [32,33].

According to Karakas et al. findings, the size of the widths of Genoa, body, splenium, and height of the corpus callosum were determined to be $13.28 \pm 2.10,7.64 \pm 1.07,12.52 \pm 1.35$, and $25.47 \pm 2.20 \mathrm{~mm}$ in females, respectively, whereas, the same measurements were $13.23 \pm 2.41,6.89 \pm 2.12,11.90 \pm 1.94$, and $25.03 \pm 3.38 \mathrm{~mm}$ in males, respectively. Due to these findings, Evans ratios were $0.25 \pm 1.90$ and $0.25 \pm 1.14$ in females and males, respectively [34].
In the Prendergast et al. study, male subjects were significantly $[F(1,303)=6.37, P<0.012]$ older, on average, than female subjects. There was no handedness significance difference between male subjects [35].

According to Bruner et al. (2012) findings, the differences in measurement and shape of CC between men and women were related to the brain size [36].

Luders et al. (2014) showed the correlation between callosal thickness and brain size in men and women [37].

In contrast, Ardekani et al. (2013) found that the whole CC area was significantly larger in females than males in a linear model, even when matching the male and female participants was done by total brain size [38].

Our previous studies on brain size, head and face size using cephalometry indicated ethnical variation between Turkmen and native Fars people [25-27].

Indeed, according to our previous study, using MRI method in the north of Iran, the size of CC in males was higher than that in females but this difference was not significant, although there was a positive significant correlation between brain longitudinal diameter and length of CC [14].

\section{Conclusion}

This study showed that the corpus callosum parameters vary in different ethnical groups in Gorgan, north of Iran.

\section{Conflicts of Interest}

The authors declare that they have no conflicts of interest.

\section{Acknowledgments}

This study was approved by Research Department of Golestan University of Medical Sciences, Gorgan, Iran. Also, the authors acknowledge Kowsar MRI Center for its cooperation in this study.

\section{References}

[1] S. Mourgela, S. Anagnostopoulou, A. Sakellaropoulos, and A. Gouliamos, "An MRI study of sex- and age-related differences in the dimensions of the corpus callosum and brain," NEUROANATOMY, vol. 6, pp. 63-65, 2007.

[2] L. K. Paul, D. Van Lancker-Sidtis, B. Schieffer, R. Dietrich, and W. S. Brown, "Communicative deficits in agenesis of the corpus callosum: Nonliteral language and affective prosody," Brain and Language, vol. 85, no. 2, pp. 313-324, 2003.

[3] M. Quigley, D. Cordes, P. Turski et al., "Role of the corpus callosum in functional connectivity," American Journal of Neuroradiology, vol. 24, no. 2, pp. 208-212, 2003.

[4] A. S. Yasar, E. S. Monkul, R. B. Sassi et al., "MRI study of corpus callosum in children and adolescents with bipolar disorder," Psychiatry Research: Neuroimaging, vol. 146, no. 1, pp. 83-85, 2006.

[5] S. J. Teipel, W. Bayer, G. E. Alexander et al., "Progression of corpus callosum atrophy in Alzheimer disease," JAMA Neurology, vol. 59, no. 2, pp. 243-248, 2002. 
[6] H. Yamauchi, H. Fukuyama, and H. Shio, "Corpus callosum atrophy in patients with leukoaraiosis may indicate global cognitive impairment," Stroke, vol. 31, no. 7, pp. 1515-1520, 2000.

[7] F. Tomaiuolo, M. Di Paola, B. Caravale, S. Vicari, M. Petrides, and C. Caltagirone, "Morphology and morphometry of the corpus callosum in Williams syndrome: A TI-weighted MRI study," NeuroReport, vol. 13, no. 17, pp. 2281-2284, 2002.

[8] K. Von Plessen, A. Lundervold, N. Duta et al., "Less developed corpus callosum in dyslexic subjects - A structural MRI study," Neuropsychologia, vol. 40, no. 7, pp. 1035-1044, 2002.

[9] K. J. Plessen, T. Wentzel-Larsen, K. Hugdahl et al., "Altered interhemispheric connectivity in individuals with Tourette's disorder," The American Journal of Psychiatry, vol. 161, no. 11, pp. 2028-2037, 2004.

[10] S. J. Teipel, M. B. Schapiro, G. E. Alexander et al., "Relation of corpus callosum and hippocampal size to age in nondemented adults with Down's syndrome," The American Journal of Psychiatry, vol. 160, no. 10, pp. 1870-1878, 2003.

[11] A. L. T. Lacerda, P. Brambilla, R. B. Sassi et al., "Anatomical MRI study of corpus callosum in unipolar depression," Journal of Psychiatric Research, vol. 39, no. 4, pp. 347-354, 2005.

[12] K. L. Narr, T. D. Cannon, R. P. Woods, P. M. Thompson, S. Kim, D. Asunction et al., "Genetic contributions to altered callosal morphology in schizophrenia," The Journal of neuroscience : the official journal of the Society for Neuroscience, vol. 22, no. 9, pp. 3720-3729, 2002.

[13] P. M. Thompson, R. A. Dutton, K. M. Hayashi et al., “3D mapping of ventricular and corpus callosum abnormalities in HIV/AIDS," NeuroImage, vol. 31, no. 1, pp. 12-23, 2006.

[14] M. R. Mohammadi, P. Zhand, B. M. Moghadam, and M. J. Golalipour, "Measurement of the corpus callosum using magnetic resonance imaging in the North of Iran," Iranian Journal of Radiology, vol. 8, no. 4, pp. 150-155, 2012.

[15] P. Bermudez and R. J. Zatorre, "Sexual dimorphism in the corpus callosum: Methodological considerations in MRI morphometry," NeuroImage, vol. 13, no. 6, pp. 1121-1130, 2001.

[16] E. Luders, K. L. Narr, E. Zaidel, P. M. Thompson, and A. W. Toga, "Gender effects on callosal thickness in scaled and unscaled space," NeuroReport, vol. 17, no. 11, pp. 1103-1106, 2006.

[17] E. Luders, D. E. Rex, K. L. Narr et al., "Relationships between sulcal asymmetries and corpus callosum size: Gender and handedness effects," Cerebral Cortex, vol. 13, no. 10, pp. 1084-1093, 2003.

[18] B. S. Peterson, P. A. Feineigle, L. H. Staib, and J. C. Gore, "Automated measurement of latent morphological features in the human corpus callosum," Human Brain Mapping, vol. 12, no. 4, pp. 232-245, 2001.

[19] E. V. Sullivan, A. Pfefferbaum, E. Adalsteinsson, G. E. Swan, and D. Carmelli, "Differential rates of regional brain change in callosal and ventricular size: A 4-year longitudinal MRI study of elderly men," Cerebral Cortex, vol. 12, no. 4, pp. 438-445, 2002.

[20] K. Okamoto, J. Ito, and S. Tokiguchi, "The MR findings on the corpus callosum of normal young volunteers," Nippon Igaku Hoshasen Gakkai zasshi. Nippon acta radiologica, vol. 50, no. 8, pp. 954-963, 1990.

[21] S. Takeda, Y. Hirashima, H. Ikeda, H. Yamamoto, M. Sugino, and S. Endo, "Determination of indices of the corpus callosum associated with normal aging in Japanese individuals," Neuroradiology, vol. 45, no. 8, pp. 513-518, 2003.
[22] T. Gupta, B. Singh, K. Kapoor, M. Gupta, and S. Kochhar, "Age and sex related variations in corpus callosal morphology.", Nepal Medical College journal : NMCJ, vol. 10, no. 4, pp. 215221, 2008.

[23] T. Gupta, B. Singh, K. Kapoor, M. Gupta, and S. Kochhar, "Normative data of corpus callosal morphology in a NorthWest Indian population - An autopsy and MRI study," Journal of Nepal Medical Association, vol. 48, no. 173, pp. 46-51, 2009.

[24] J. Suganthy, L. Raghuram, B. Antonisamy, S. Vettivel, C. Madhavi, and R. Koshi, "Gender- and age-related differences in the morphology of the corpus callosum," Clinical Anatomy, vol. 16, no. 5, pp. 396-403, 2003.

[25] M. J. Golalipour, "The effect of ethnic factor on cephalic index in 17-20 years old females of north of Iran," International Journal of Morphology, vol. 24, no. 3, pp. 319-322, 2006.

[26] M. J. Golalipour, M. Jahanshaei, and K. Haidari, "Estimation of Cranial Capacity in 17-20 Years Old in South East of Caspian Sea Border (North of Iran)," International Journal of Morphology, vol. 23, no. 4, pp. 301-304, 2005.

[27] M. J. Golalipour, M. Jahanshahi, and K. Haidari, "Morphological evaluation of head in Turkman males in Gorgan-North of Iran," International Journal of Morphology, vol. 25, no. 1, pp. 99102, 2007.

[28] R. Estruch, J. M. Nicolás, M. Salamero et al., "Atrophy of the corpus callosum in chronic alcoholism," Journal of the Neurological Sciences, vol. 146, no. 2, pp. 145-151, 1997.

[29] E. V. Sullivan, M. J. Rosenbloom, J. E. Desmond, and A. Pfefferbaum, "Sex differences in corpus callosum size: Relationship to age and intracranial size," Neurobiology of Aging, vol. 22, no. 4, pp. 603-611, 2001.

[30] C. M. Tuncer, E. S. Hatipoğlu, and M. Özateş, "Sexual dimorphism and handedness in the human corpus callosum based on magnetic resonance imaging," Surgical and Radiologic Anatomy, vol. 27, no. 3, pp. 254-259, 2005.

[31] T. Lee, H. Hwang, A. De Salles, C. Mattozo, A. G. Pedroso, and E. Behnke, "Inter-Racial, Gender and Aging Influences in the Length of Anterior Commissure-Posterior Commissure Line," Journal of Korean Neurosurgical Society, vol. 43, no. 2, p. 79, 2008.

[32] R. L. Holloway, P. J. Anderson, R. Defendini, and C. Harper, "Sexual dimorphism of the human corpus callosum from three independent samples: Relative size of the corpus callosum," American Journal of Physical Anthropology, vol. 92, no. 4, pp. 481-498, 1993.

[33] J. Klekamp, A. Riedel, C. Harper, and H. J. Kretschmann, "Morphometric study on the postnatal growth of the hippocampus in Australian Aborigines and Caucasians," Brain Research, vol. 549, no. 1, pp. 90-94, 1991.

[34] P. Karakaş, Z. Koç, F. Koç, and M. Gülhal Bozkir, "Morphometric MRI evaluation of corpus callosum and ventricles in normal adults," Neurological Research, vol. 33, no. 10, pp. 1044-1049, 2011.

[35] D. M. Prendergast, B. Ardekani, T. Ikuta et al., "Age and sex effects on corpus callosum morphology across the lifespan," Human Brain Mapping, vol. 36, no. 7, pp. 2691-2702, 2015.

[36] E. Bruner, J. M. De la Cuétara, R. Colom, and M. MartinLoeches, "Gender-based differences in the shape of the human corpus callosum are associated with allometric variations," Journal of Anatomy, vol. 220, no. 4, pp. 417-421, 2012.

[37] E. Luders, A. W. Toga, and P. M. Thompson, "Why size matters: Differences in brain volume account for apparent sex 
differences in callosal anatomy. The sexual dimorphism of the corpus callosum," NeuroImage, vol. 84, pp. 820-824, 2014.

[38] B. A. Ardekani, K. Figarsky, and J. J. Sidtis, "Sexual dimorphism in the human corpus callosum: An MRI study using the OASIS brain database," Cerebral Cortex, vol. 23, no. 10, pp. 2514-2520, 2013. 


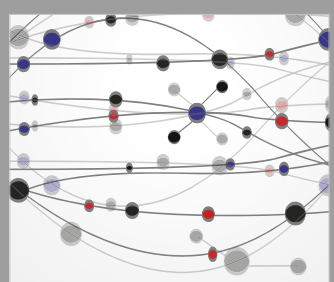

The Scientific World Journal
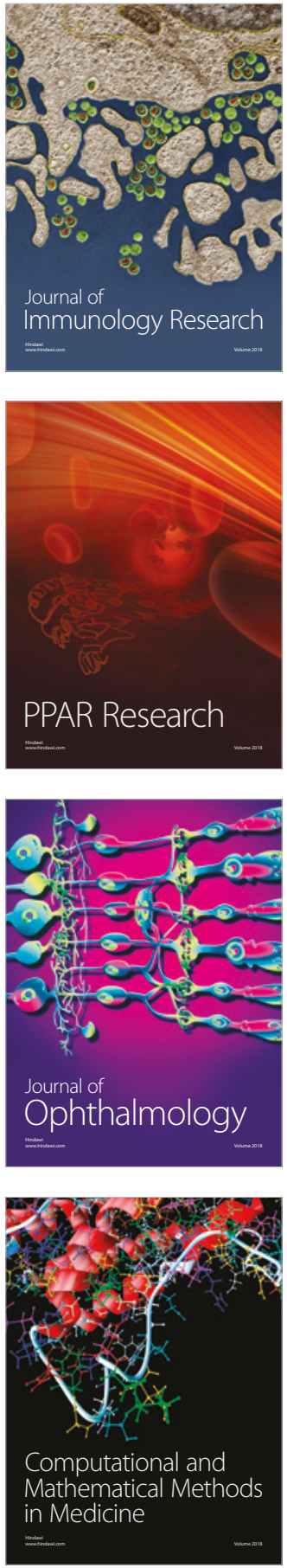

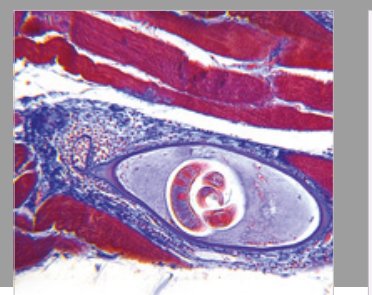

Gastroenterology Research and Practice

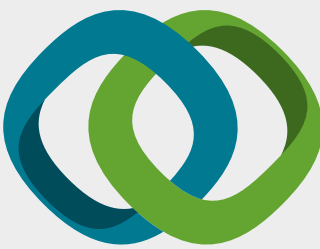

\section{Hindawi}

Submit your manuscripts at

www.hindawi.com
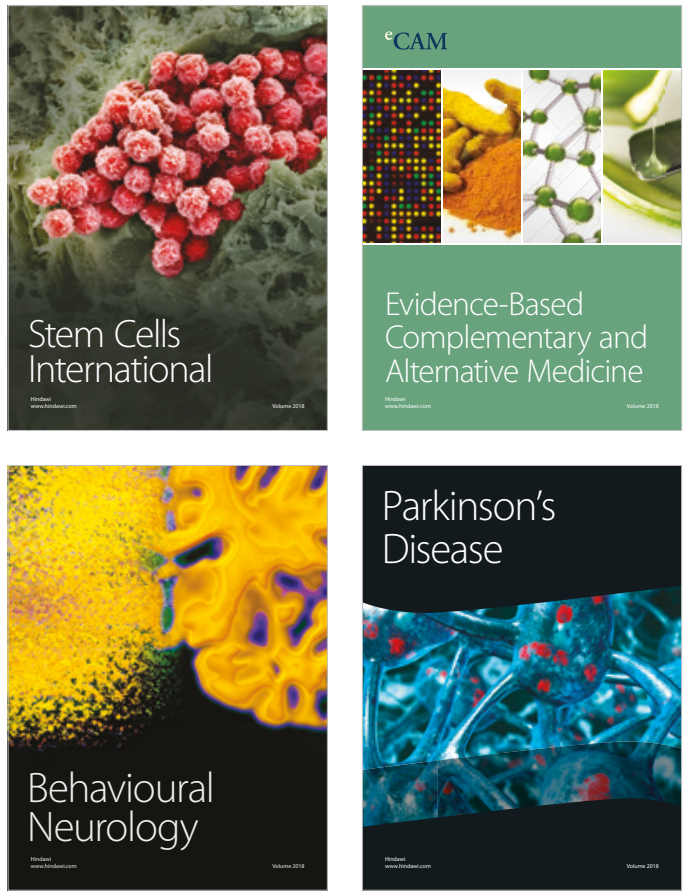

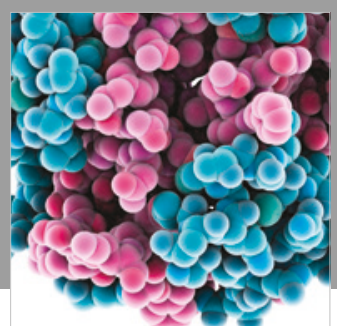

ournal of

Diabetes Research

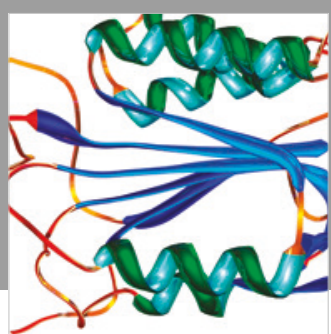

Disease Markers
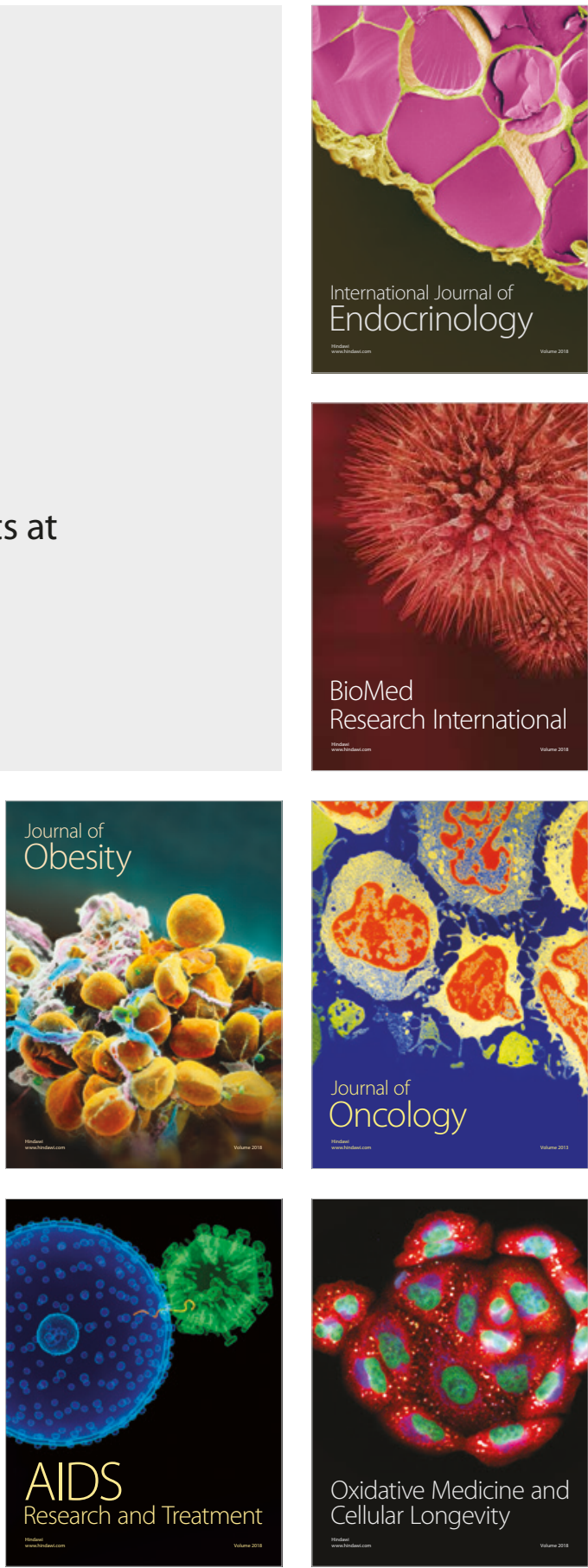